* Mestranda em Direito Empresarial pela Universidade do Estado do Rio de Janeiro (UERJ) (linha de pesquisa Empresa e Atividades Econômicas). Professora da graduação e pósgraduação da Universidade Estácio de Sá. Professora de Direito Empresarial da Escola da Magistratura do Estado do Rio de Janeiro, integrante do programa de Monitoria Acadêmica. Advogada consultora.

E-mail: simonediasmenezes@uol. com.br;

**Doutorado em Saúde Pública pela Escola Nacional de Saúde Pública Sérgio Arouca (ENSP) da Fundação Oswaldo Cruz (FIOCRUZ), Mestre em Direito pela Universidade Gama Filho (UGF), Bacharel em Direito pela Universidade do Estado do Rio de Janeiro (UERJ). Parecerista da Seção de Propriedade Intelectual da Revista Semestral de Direito Empresarial (RSDE), Revista Quaestio Iuris, da Revista da Faculdade de Direito (RFD) da UERJ e do Conselho Nacional de Pesquisa e Pós-Graduação em Direito (CONPEDI). Professor Adjunto de Direito Comercial. Professor do Programa de PósGraduação em Direito (PPGD) e da Graduação da Faculdade de Direito da UERJ.

E-mail: santanna44@gmail.com;

\section{Sociedade Limitada E Eireli: Uma Análise Sobre A Divisão Dos Resultados}

\author{
Limited Liability Company And Eireli: An Analysis Of \\ The Division Of Profit
}

\section{Simone Menezes Gantois* Leonardo Sant'anna**}

Como citar: GANTOIS, Simone Menezes; SANT'ANNA, Leonardo. Sociedade limitada e EIRELI: uma análise sobre a divisão dos resultados. Scientia Iuris, Londrina, v. 25, n. 1, p. 6886, mar. 2021. DOI: $10.5433 / 2178-8189.2018 v 25 n 1 p 68$. ISSN: 2178-8189.

Resumo: O presente estudo faz uma análise da divisão dos resultados na sociedade limitada e na EIRELI, a partir de suas características legais principais, mostrando as possibilidades de divisão do resultado pouco exploradas que esses tipos societários podem apresentar sobre o tema. Fez-se um breve estudo acerca desses dois tipos societários, e em tópico próprio, destacou-se a divisão de resultados, primeiro em relação ao prejuízo e risco do exercício da atividade e, em seguida, em relação a lucratividade e sua partilha entre o(s) sócio(s), apresentando as possibilidades contratuais sobre o tema, com relação aos dois modelos societários. Ao final, apresentou-se uma conclusão onde se demonstrou para onde ainda é possível juridicamente avançar com relação a divisão de resultados, dada as possibilidades que decorrem desses dois modelos societários. Para demonstração dessa orientação, foi realizada uma pesquisa teórica, utilizando-se, como método, a fonte jurídica primária; a lei, parametrizando-a com doutrina especializada, bem como as orientações seguidas pelos tribunais brasileiros.

Palavras-chave: Direito societário. Sociedade. Sociedade limitada. EIRELI. Lucro. Resultado.

\begin{abstract}
This study analyzes the division of profits in the limited liability company and in the EIRELI, starting from its main legal characteristics, showing the little explored possibilities of dividing the profit that these modes of companies may present on the subject. A brief study was made about these two corporate configurations, and in a specific topic, the division of results was highlighted, first in relation to the loss and risk and then, in
\end{abstract}


relation to the profitability and its sharing among the partner(s), presenting the contractual possibilities of the subject, regarding the two corporate models. At the end, a conclusion was presented showing where it is still legally possible to advance regarding the division of results, given the possibilities arising from these two corporate models. To demonstrate this orientation, a theoretical research was conducted, using as its method the bibliography review of law, specialized doctrines and scientific articles, as well as guidelines followed by Brazilian courts.

Keywords: Corporate law. Company. Limited liability company. EIRELI. Profit division. 


\section{INTRODUÇÃO}

A sociedade limitada é um tipo societário muito utilizado no Rio de Janeiro ${ }^{1}$

Isso porque, é um tipo societário com uma boa maleabilidade e que serve para o desenvolvimento de pequenas ou grandes atividades econômicas, empresárias ou não, assim como permite criar estruturas societárias simples ${ }^{2}$, ou complexas, dependendo para tanto, da vontade do cliente e da qualidade do advogado especialista.

Como os empreendimentos no Brasil $^{3}$ eram e ainda são pequenos, a grande maioria das sociedades eram criadas com apenas dois sócios. Era comum que um deles fosse apenas de fachada ${ }^{4}$, com $1 \%$ (um por cento) ou $2 \%$ (dois por cento) do capital social, e assim compondo a pluralidade de sócios que era legalmente exigida e conseguindo, com isso, fugir do regime jurídico ilimitado de responsabilidade do empresário individual pelos riscos da atividade desenvolvida.

Durante muito tempo a sociedade limitada ocupou isolada esse protagonismo, até que a partir de 2011, com o advento da Lei $\mathrm{n}^{0}$ 12.441/11, com vigência a partir de 09/01/2012, foi trazida para o ordenamento jurídico brasileiro a figura da Empresa Individual de Responsabilidade Limitada (EIRELI), que só pode ter um sócio, tem personalidade jurídica e o regime de responsabilidade é limitado ao capital social.

A partir desse marco legal esse protagonismo, de certo modo, passou numericamente a ser dividido. EIRELI e sociedade limitada passaram, quase parelha, a encabeçar os números de novas sociedades ${ }^{5}$ constituídas, mas ainda assim a sociedade limitada continuou apresentando uma ligeira vantagem, que muito provavelmente estava ligada a obrigatoriedade do capital social mínimo exigido na EIRELI, diferentemente do que ocorre na sociedade limitada.

No início do ano passado, via Medida Provisória $n^{\circ} 881 / 19$, publicada no Diário Oficial de 30/04/2019, regulamentada pelo Departamento de Registro Empresarial e Integração (DREI), pela IN DREI $n^{\circ} 63$, revogada pela IN DREI ${ }^{\circ} 81 / 20$, publicada no Diário Oficial de 14/06/2019 e que veio a ser convertida na Lei $\mathrm{n}^{\circ} 13.874 / 19$, apelidada de Lei da Liberdade Econômica, alterouse, entre outras coisas, o regime jurídico da sociedade limitada passando a permitir que esse tipo societário seja constituído por apenas um sócio.

Comparando os dados oficiais da Junta Comercial do Estado do Rio de Janeiro (JUCERJA) ${ }^{6}$, estabelecendo uma relação dos primeiros meses de 2019 e de 2020, que exibe um período antes e depois da entrada em vigor da Lei $\mathrm{n}^{\mathrm{o}} 13.874 / 19$, no qual se passou a admitir a sociedade limitada unipessoal permanente, o tipo societário limitada voltou a ser protagonista entre os tipos societários disponíveis no ordenamento brasileiro.

Fazendo um recorte apenas do mês de janeiro/2019, antes da MP n ${ }^{\circ} 881 / 19$, observa-se foram abertas 1.499 sociedades limitadas, para 1.363 EIRELI, já em janeiro/2020, após a edição da Medida Provisória, foram abertas 1.993 sociedades limitadas para 1.177 EIRELI. Como se vê, a sociedade limitada voltou a ser a preferida, dos fluminenses pelo menos.

Embora a sociedade limitada lidere a preferência hoje no Estado do Rio de Janeiro, a

1 Essa pesquisa levou em consideração dados estatísticos da Junta Comercial do Estado do Rio de Janeiro.

2 Constituídas por contratos sociais feitos com base em minutas disponíveis nos sites das Juntas Comerciais dos Estados da Federação ou na rede mundial de computadores e, na maioria dos casos, redigida por um contador, que não é advogado. Isso quando não faz sem nenhuma assessoria. Essa é, inclusive, a realidade dos pequenos empreendimentos no Brasil.

3 Segundo a cartilha com o Perfil das Microempresas e Empresas de Pequeno Porte, elaborada pelo SEBRAE, em abril são responsáveis por 54\% dos empregos formais, (SEBRAE, 2018, p. 4), no Brasil elas representam 98,5\% do total de empresas privadas e respondem por $28 \%$ do PIB.

4 Também chamados de homens de palha, expressão usada para fazer referência a sócio que participa da sociedade apenas com o fim compor a pluralidade de sócios, conforme exposição de motivos da Lei $\mathrm{n}^{\circ}$ 6.404/76, quando justifica a regulamentação da subsidiária integral. Exposição de Motivos 196, de 24/06/1976, do Ministério da Fazenda (BRASIL, 1976).

5 A EIRELI foi incluída como sociedade por ser essa a adesão dogmática do autor deste trabalho.

6 Dados extraídos da Estatística Comparativa da JUCERJA 2019/2020 (JUCERJA, 2020). 
EIRELI continua contando com a simpatia dos empreendedores, tornando relevante o objeto deste estudo. Mas, afinal, para onde vamos?

Partindo da importância contemporânea destes dois tipos societários, que mais adiante serão analisados em suas características gerais, buscaremos aprofundá-los, em um viés pouco explorado pela doutrina, que é a distribuição de seus resultados entre os sócios e novas possibilidades e perspectivas que podem dele derivar.

\section{A SOCIEDADE LIMITADA}

A gênese da sociedade limitada é alemã. Em 1892, foi criada e disciplinada sob o nome sociedade de responsabilidade limitada (Gesellschaft mit beschränkter Haftung - GmbH), tendo sido seguida por Portugal, em 1901, que a denominou sociedade por quotas de responsabilidade limitada.

Inspirado na legislação portuguesa, o Brasil somente aderiu a esse tipo societário em 1919 através do Decreto ${ }^{\circ}$ 3.708/1919, apropriando-se da mesma nomenclatura dos portugueses. Essa legislação foi revogada pela entrada em vigor, da Lei $n^{\circ} 10.406 / 2002$, o Código Civil de 2002 que passou a denominá-la, simplesmente, sociedade limitada e regulá-la a partir do artigo 1.052 ao artigo 1.087 do Código Civil.

A sociedade limitada nasceu como uma pessoa jurídica pluripessoal, porque pressupunha ser formada, no mínimo por dois sócios, que podiam ser pessoas naturais ou pessoas jurídicas. No entanto, a pluripessoalidade não é mais um traço característico da sociedade limitada, em razão das alterações normativas introduzidas no ordenamento jurídico brasileiro em 2019, com a publicação da Lei $n^{\circ}$ 13.874/19, apelidada de Lei da Liberdade Econômica (BRASIL, 2019). Essa lei, alterou o artigo 1.052 do Código Civil introduzindo ao texto normativo dois parágrafos que assim dispõem:

Art. 1.052. [...]

$\S 1 .^{\circ}$ A sociedade limitada pode ser constituída por 1 (uma) ou mais pessoas.

$\S 2 .^{\circ} \mathrm{Se}$ for unipessoal, aplicar-se-ão ao documento de constituição do sócio único, no que couber, as disposições sobre o contrato social (BRASIL, 2002).

Como se vê, desde 2019 já é possível constituir uma sociedade limitada unipessoal permanente, espancando de uma vez por todas a ideia ultrapassada de que o conceito de sociedade pressupõe pluralidade de sócios, opinião externada também por Alves (2014, p. 139) e Campinho (2016, p. 250).

O contrato social tem natureza jurídica de contrato plurilateral, plurilateralidade essa não relacionada com sinalagma, mas sim com a multiplicidade de relações que dele pode emanar.

A teoria do direito obrigações e a teoria geral dos contratos trabalham com a ideia de que os negócios jurídicos têm no mínimo duas partes porque elas manifestam sua vontade convergente para celebração das obrigações ali pactuadas, que podem ser mútuas ou não, e gerará a clássica nomenclatura classificatória dos negócios jurídicos em unilaterais e bilaterais.

No contrato social as relações se estabelecem de forma diferente, porque, apesar do(s) sócio(s) estabelecer(em) inicialmente as regras que serão transpostas para o contrato, o(s) sócio(s) celebra $(\mathrm{m})$ o contrato com a sociedade e não com os outros sócios. Tanto isso é assim que quando um sócio, por qualquer razão de direito, deixa a sociedade o instituto se denomina: resolução da sociedade com relação a um sócio e quem paga o valor patrimonial da participação do sócio que deixa a sociedade é a própria sociedade e não os demais sócios.

A partir dessa alteração normativa, alguns comentários têm sido feitos acerca da extinção da EIRELI, contudo não foi essa a escolha que fez o legislador, que poderia ter, nessa oportunidade revogado o artigo 980-A do Código Civil. Muito pelo contrário, ele além de não ter revogado ainda 
introduziu um novo parágrafo ao dispositivo, mantendo-o vivo no ordenamento jurídico. A maior questão por trás disso é se a EIRELI continuará sendo útil, mas a vista dos dados estatísticos que introduziram esse trabalho parece que sim.

Neste tipo societário seus sócios são chamados quotistas e sua responsabilidade é restrita ao valor das suas quotas e solidária pela integralização do capital social. Esse regime para ser melhor compreendido deve ser dividido em duas partes, pois quando o artigo 1.052 do Código Civil diz que a responsabilidade de cada sócio é restrita ao valor de suas quotas, está se referindo a responsabilidade que cada sócio tem com a sociedade, pelo capital que subscreveu e se comprometeu a integralizar, ao passo que ao dizer que todos respondem solidariamente pela integralização do capital social, o legislador refere a responsabilidade que todos os sócios têm com terceiros pelas obrigações sociais e essa responsabilidade é solidária apenas pelo valor do capital social a integralizar. Isso significa dizer que essa solidariedade vai durar apenas enquanto a sociedade tiver montante de capital social a integralizar, e uma vez integralizado, não há que se falar em responsabilidade dos sócios pelas obrigações da sociedade em decorrência do seu regime societário ${ }^{7}$.

Esse modelo societário não admite sócios que contribuam com serviços por expressa vedação legal, artigo 1.055, $\S 2^{\circ}$ do Código Civil. Exige-se dinheiro ou bens suscetíveis de avaliação em dinheiro.

Corresponde ao tipo societário mais flexível disponível no ordenamento jurídico vigente porque permite desempenhar atividade econômica tipicamente empresarial, registrando-se, nesse caso no Registro Público de Empresas Mercantis (RPEM) ou atividade econômica não empresária, caracterizando-se, assim como uma sociedade simples, e, por isso, seu ato constitutivo deve ser registrado no Registro Civil de Pessoas Jurídica (RCPJ), como prescreve o artigo 1.150 do Código Civil. Quanto a isso não há dúvida, o artigo 983 do Código Civil é claro ao dizer que a sociedade simples, pode escolher a sociedade limitada como um dos seus possíveis regimes jurídicos.

A doutrina diverge quanto a natureza jurídica da sociedade limitada, se ela seria sociedade de pessoas ou se ela seria uma sociedade de capital. Campinho (2016, p. 63) entende que a sociedade limitada é uma sociedade de pessoas porquanto tem presente a qualidade pessoal do sócio e caráter intuitu personae, do affectio societatis. Para Borba (2012, p. 80) não é possível definir a natureza jurídica da sociedade limitada a priori, porque isso dependerá de uma análise pormenorizada do contrato social. A depender da forma como vier a ser concebido o contrato social, suas cláusulas contratuais darão indícios da natureza jurídica assumida, se de pessoas ou de capitais (cessão de cotas, penhora, falecimento de sócio) e, por essa razão sua natureza jurídica seria híbrida.

De fato, a plasticidade das regras dispositivas que integram seu regime jurídico permite que a sociedade limitada assuma o perfil que melhor lhe aprouver a partir escolhas sobre termas que denotariam affectio societatis ${ }^{8}$, com caráter intuitu personae, ou intuitu pecunia.

Apesar disso, assumimos um posicionamento intermediário, que apesar da plasticidade do regime jurídico da sociedade limitada, que possui regras dispositivas, se se reconhecer e aderir automaticamente as regras gerais que lhe são próprias essa sociedade será uma sociedade de pessoas. Um exemplo elucidativo, é a opção ou não pela regência supletiva das normas de sociedade anônima facultada pelo artigo 1.053, parágrafo único do Código Civil, que depende de previsão expressa no contrato social, essa opção, provavelmente, ensejaria um perfil de sociedade de capitais, enquanto que, se o contrato for silente prevalecerá a aplicação das normas do regime jurídico das sociedades do tipo simples, que possuem regras que são absolutamente incompatíveis com um perfil capitalista.

7 Não se está a falar de outras hipóteses que podem ensejar a responsabilização de um sócio pelas obrigações sociais como em caso de aplicação da teoria da desconsideração da personalidade jurídica ou responsabilização por atos ultra vires na condição de sócio e administrador da sociedade.

8 Animus contrahendi societatis, segundo Negrão (2015, p. 337). 
A sociedade limitada é uma sociedade contratual, uma vez que seus atos constitutivos se consubstanciam em um contrato social, que exige forma escrita e cujas cláusulas contratuais essenciais obedecem, no que couber, o disposto no artigo 997 do Código Civil por força do disposto no artigo 1.054 do mesmo diploma legal. Quando a sociedade limitada for unipessoal o contrato social somente terá cláusulas que forem compatíveis com a unipessoalidade, como determina o $§ 2^{\circ}$ do artigo 1.052 do Código Civil.

Nela é possível escolher entre duas espécies de nome empresarial, firma ou denominação. Com a permissão de constituição de sociedade limitada unipessoal, passou a ser possível, a adoção de firma individual para esse caso, permanecendo viva a possibilidade de escolher a firma coletiva ou social, obedecendo estritamente o regramento do artigo 1.158 do Código Civil, acrescida em qualquer caso da expressão Limitada por extenso ou abreviadamente (LTDA).

O capital social é divido em quotas de valores iguais ou desiguais, distribuindo-se uma ou diversas entre o(s) sócio(s), tal como dispõe o artigo 1.055, caput do Código Civil. Essas informações constituem cláusula obrigatória do contrato social (artigo 997, IV do Código Civil).

Feitas essas considerações passemos a análise da EIRELI.

\section{A EMPRESA INDIVIDUAL DE RESPONSABILIDADE LIMITADA - EIRELI}

A EIRELI foi introduzida ao ordenamento jurídico brasileiro pela Lei ${ }^{\circ} 12.441 / 11$ que acrescentou o artigo 980-A ao Código Civil, resultado de dois projetos de lei que tramitaram simultaneamente no Congresso Nacional, o PL 4.605/2009 e o PL 4.953/2009, cujos pormenores são muito bem detalhados por Alves (2014, p. 141), no artigo "A Empresa Familiar de Responsabilidade Limitada".

A EIRELI é uma pessoa jurídica e não se confunde com empresário individual porque este é pessoa física, dotado de patrimônio único diferentemente da EIRELI, que, ao adquirir personalidade jurídica, passa a ter autonomia patrimonial, distinguindo o seu próprio patrimônio, do patrimônio pessoal do sócio que a integra.

Em sendo uma pessoa jurídica, qual a sua natureza jurídica? Não existe consenso na doutrina com relação a isso.

O legislador pátrio, nitidamente, fez uma escolha de sua orientação dogmática e não está só, Nunes (2014, p. 66), Tomazette (2017, p. 62), Gonçalves Neto (2016, p. 127), Ramos (2015, p. 44), e o Conselho da Justiça Federal, através de seus enunciados, defendem que a EIRELI não é sociedade, mas sim uma nova modalidade de pessoa jurídica — novo ente personificado necessariamente unipessoal permanente.

A posição do legislador é denunciada, em primeiro lugar, pela topografia escolhida para introduzir o instituto no Código Civil. As sociedades começam a ser reguladas a partir do Título II, do Livro II do Código Civil enquanto que a EIRELI está no Título I-A, entre o Título I que trata do Empresário Individual e o Título II que trata de Sociedade, indicando que a EIRELI não seria nem uma coisa, nem outra.

Além disso, o legislador no artigo 44 do Código Civil, que enumera quais são as pessoas jurídicas de direito privado, separou a EIRELI das sociedades, respectivamente, nos incisos VI e II, justamente porque, para o legislador, são coisas distintas, se fossem iguais não teria ele se dado ao trabalho de inseri-la, porque a palavra sociedade já constava do texto normativo. O mesmo ocorre com o artigo $3^{\circ}$ da LC 126/06 que cuida de Empresa de Pequeno Porte (EPP) e Microempresa (ME) cuja redação foi alterada pela LC 139/11 para incluir entre suas possibilidades a EIRELI, sendo que expressão sociedade empresária e sociedade simples já constavam de sua redação original;

Aos defensores, desse posicionamento, entre os quais se destaca Gonçalves Neto (2016, p. 128), os atos constitutivos da EIRELI seria uma declaração unilateral de vontade.

Abaixo, transcrevo o conteúdo dos enunciados da V Jornada de Direito Civil e I Jornada 
de Direito Comercial promovidas pelo Conselho da Justiça Federal (CJF) que indicam a orientação no sentido acima relatado:

Enunciado 469 CJF: Art. 44 e 980-A: A Empresa Individual de Responsabilidade Limitada (EIRELI) não é sociedade, mas novo ente jurídico personalizado (CJF, 2012, p. 76).

Enunciado 472 CJF: É inadequada a utilização da expressão "social” para as empresas individuais de responsabilidade limitada (CJF, 2012, p. 76).

Enunciado 3 CJF Comercial: A Empresa Individual de Responsabilidade Limitada - EIRELI não é sociedade unipessoal, mas um novo ente, distinto da pessoa do empresário e da sociedade empresária (CJF, 2013, p. 51).

Por outro lado, e ao nosso ver com razão, Alves (2014, p. 148), Travassos (2015, p. 133) e Campinho (2016, p. 250) reconhecem a EIRELI como uma sociedade unipessoal permanente, que cria um novo tipo societário. Essa orientação ignora a topografia do Código Civil e se fundamenta no fato de sempre existiram sociedades unipessoais permanentes no ordenamento jurídico, a exemplo da subsidiária integral (artigo 251 Lei n ${ }^{\circ} 6.404 / 76$ ) e a empresa pública (artigo $5^{\circ}$, II DL 200/67 e artigo $3^{\circ}$, Lei $n^{\circ} 13.303 / 16$ ), isso aliado ao fato de que após a criação da EIRELI novos modelos societários unipessoais surgirem, como a sociedade unipessoal de advocacia (artigo 15, Lei $n^{\circ} 8.906 / 94$, com redação dada pela Lei ${ }^{\circ} 13.247 / 16$ ) e a sociedade limitada, demonstrando, no mínimo, que a topografia e a posição do legislador não sobrevivem quando não encontram substrato teórico e prático9.

O que se reconhece, é que a formação da EIRELI é institucional, porque nasce da manifestação de vontade de seu único integrante, que a institui.

E, por fim, apenas como argumento de autoridade, fazendo uma interpretação literal do artigo 980-A do Código Civil, que fala em "capital social", "denominação social" e, principalmente no $\S 3^{\circ}$ que fala em "outra modalidade societária", não resiste ao canto da sereia da primeira orientação.

Permitimo-nos ser repetitivos, apesar dos estritos e breves limites deste trabalho, mas é necessário, para deixar claro nosso posicionamento. Como dito, quando analisamos a sociedade limitada unipessoal nos itens anteriores, o contrato social é o ato constitutivo adequado para formar a sociedade limitada, e toda e qualquer sociedade contratual, e a EIRELI é uma de suas espécies. O contrato social tem natureza jurídica de contrato plurilateral, mas essa plurilateralidade não tem relação com sinalagma, mas sim pela multiplicidade de relações que dele podem emanar.

Observando esse ponto, a partir da teoria do direito obrigações e a teoria geral dos contratos, verifica-se que elas trabalham a ideia de que os negócios jurídicos têm no mínimo duas partes porque elas manifestam vontade convergente para celebração das obrigações ali pactuadas. Isso é do jogo dos negócios jurídicos, sobretudo os bilaterais ou sinalagmáticos, que estabelecem obrigações mútuas entre os contratantes. No entanto, no contrato social, as relações se estabelecem de forma diferente, porque, apesar do(s) sócio(s) estabelecer(em) inicialmente as regras que serão transpostas para o contrato, $\mathrm{o}(\mathrm{s})$ sócio(s) celebra(m) o contrato com a sociedade não com o outro 9 Em 2016, o Estatuto da OAB (Lei $n^{\circ}$ 8.906) foi alterado, pela Lei $n^{\circ} 13.247 / 16$, dando nova redação ao artigo 15 e criando a sociedade unipessoal de advocacia. E mais recentemente, a Lei $n^{\circ} 13.874 / 19$, alterou a redação do artigo 1.052 do Código Civil para introduzir dois novos parágrafos nos quais um deles passa a permitir que a sociedade limitada unipessoal, conforme já analisado. 
sócio. Tanto isso é assim que quando um sócio por qualquer razão de direito deixa a sociedade o instituto se denomina: resolução da sociedade com relação a um sócio e quem paga o valor da participação do sócio que deixa a sociedade é a própria sociedade e não os demais sócios. Nunca é demais lembrar que resolução é uma espécie do gênero extinção do contrato, reguladas em Capítulo próprio no Código Civil dos artigos 472 a 480.

Em sendo constituída por um contrato social, seus requisitos devem obedecer, aos requisitos gerais e específicos inerentes aos contratos sociais, especificamente e, no que couber, ao disposto no artigo 997, com base no artigo 1.054 cuja observância é delineada pelo artigo 980-A, $\S 6^{\circ}$, todos do Código Civil.

Por ser uma forma societária a EIRELI adquirirá personalidade jurídica com o registro de seus atos constitutivos no órgão competente, tal como enuncia os artigos 45 e 985 do Código Civil. Nesse sentido também, o enunciado 471 da V Jornada de Direito Civil do CJF: "Enunciado 471 CJF: Os atos constitutivos da EIRELI devem ser arquivados no registro competente, para fins de aquisição de personalidade jurídica. A falta de arquivamento ou de registro de alterações dos atos constitutivos configura irregularidade superveniente." (CJF, 2012, p. 76).

E qual o órgão competente para registro? O registro depende, em regra, da natureza jurídica da sociedade. Em se tratando de uma sociedade empresária, o órgão competente será o RPEM e em se tratando de uma sociedade simples o órgão competente será RCPJ.

A questão que precisa ser analisada é se a EIRELI admite ser apenas empresária ou se ela também admitiria ter um objeto simples (não empresarial). A grande maioria da doutrina, não enfrenta essa questão. Contudo a doutrina ${ }^{10}$, não vê impedimento para que a EIRELI também tenha natureza simples e, por conseguinte seja registrada no RCPJ, não só pela natureza contratual delas, como também em razão das disposições dos $\S \S 5^{\circ}$ e $6^{\circ}$ do artigo 980-A do Código Civil, que é ampliativo, entre os autores que defendem esse posicionamento destaca-se, Nunes (2014, p. 85), Travassos (2015, p. 169) e Alves (2014, p. 157), como se transcreve os argumentos deste último:

\section{$[\ldots]$}

$\mathrm{O} \S 5^{\circ}$ do art. 980-A na parte em que se refere à "prestação de serviço de qualquer natureza" bem como à "cessão de direitos patrimoniais de autor ou de imagem, nome, marca ou voz de que seja detentor o titular da pessoa jurídica, vinculados a atividade profissional" estabelece nítida associação com o parágrafo único do art. 966 do Código Civil. Neste dispositivo está consignado que não é empresarial a atividade intelectual de natureza científica, literária ou artística exercida em caráter profissional pela pessoa natural, ainda que com o concurso de colaboradores ou auxiliares, exceto se constituir elemento de empresa. Tal ressalva não está contida no $\S 5^{\circ}$ do art. 980-A, que é ampliativo e não restritivo, como ficou patente na sua segunda e última alteração.

[...] (ALVES, 2014, p. 157, grifo nosso).

Do ponto de vista prático a EIRELI vem sendo amplamente registrada no Registro Civil de Pessoa Jurídica da Capital do Estado do Rio de Janeiro e no de São Paulo também.

Apesar de óbvio, esclarecemos que não há dissenso na doutrina sobre a possibilidade da EIRELI exercer atividade empresarial e, nesse caso o registro próprio será o RPEM, tal como enuncia o artigo 1.150 do Código Civil.

10 Citando Gonçalves Neto (2016, p. 125) como voz dissonante. 
Com relação ao produtor rural o enunciado 62 da II Jornada de Direito Comercial, trata especificamente sobre o tema ${ }^{11}$ : "Enunciado 62 CJF Comercial: O produtor rural, nas condições mencionadas do artigo 971 do CCB, pode constituir EIRELI." (CJF, 2015, p. 2).

A nomenclatura escolhida pelo legislador para denominar essa nova forma societária, foi infeliz e só serviu para confundir ainda mais o aplicador do direito, que muitas vezes não é um advogado e muito menos especialista. A expressão Empresa, contida no nome do instituto, é um conceito jurídico abstrato ${ }^{12}$ e que não tem personalidade jurídica, porquanto intangível, e passa ser a utilizado para formar um nome de um tipo societário, que vai se tornar, preenchidos os requisitos legais, uma pessoa jurídica. E não é só, ao utilizar a palavra individual no nome confunde o tipo societário, destinado a constituir pessoas jurídicas, com empresário individual, que é a pessoa natural que exerce a empresa. Melhor teria sido se desde o princípio tivessem apenas alterado o artigo 1.052 do Código Civil como já noticiado.

Passando para uma breve análise de suas características mais marcantes, a EIRELI por força do caput do artigo 980-A do Código Civil, deverá ter um capital social mínimo que deve ser integralizado simultaneamente a constituição da sociedade, considerando o salário mínimo nacional vigente no país à época da constituição, conforme o Manual da EIRELI que acompanha a IN DREI ${ }^{\circ} 81 / 20$, publicado no DOU 15/06/2020. A mencionada instrução normativa, inovou ao explicitar um novo posicionamento do DREI a respeito da hipótese do valor que exceder os 100 (cem) salários mínimos e em caso de aumento de capital, em ambas situações (item 5.2 e 5.2.1).

O capital social pode ser integralizado em dinheiro e em bens suscetíveis de avaliação em dinheiro, a teor do disposto no artigo 997, III do Código Civil, que enuncia as cláusulas contratuais obrigatórias do contrato social, cuja observância deve ser seguida, no que couber por força da interpretação conjugada do disposto no artigo 980-A, $\S 6^{\circ}$ e 1.054 do Código Civil. Não se admite nesse tipo societário que o sócio integralize capital social com serviço, também por uma interpretação conjugada do disposto no artigo $1.055, \S 2^{\circ}$ e $980-\mathrm{A}, \S 6^{\circ}$ do Código Civil.

A aferição do valor correspondente aos 100 (cem) salários mínimos é feito no momento do registro e há enunciados do CJF, da I Jornada de Direito Comercial nesse sentido ${ }^{13}$ : "Enunciado 4 CJF Comercial: Uma vez subscrito e efetivamente integralizado, o capital da empresa individual de responsabilidade limitada não sofrerá nenhuma influência decorrente de ulteriores alterações do salário mínimo." (CJF, 2013, p. 51).

A EIRELI só pode ter, como sócio, uma única pessoa. Essa é dicção do caput do artigo 980-A do Código Civil. O legislador foi impreciso e não apontou se era possível que pessoa física ou jurídica pudessem titularizar uma EIRELI. Em razão disso, a doutrina se dividiu, Gonçalves Neto (2016, p. 130) defende que somente pessoas naturais poderiam ser sócias e em 2012, foi editado um Enunciado CJF da V Jornada de Direito Civil ${ }^{14}$ no mesmo sentido.

No entanto, não é essa a orientação que hoje prevalece. A maioria da doutrina especializada, entre os quais destaco Alves (2014, p. 149), Nunes (2014, p. 90), Travassos (2015, p. 202), Tomazzete (2017, p. 64), sempre defenderam a possibilidade da pessoa jurídica ser titular da EIRELI, por uma razão simples, a lei não vedava. O grande problema era que na prática ninguém conseguia registrar uma EIRELI cujo único sócio fosse uma pessoa jurídica porque a legislação

11 Merece uma crítica o enunciado, acima citado, haja vista que o dispositivo correto seria o artigo 986 do Código Civil, que atribui ao registro no RPEM um triplo efeito ao ruralista: constitutivo da condição de empresário, constitutivo da aquisição da personalidade jurídica e atribuindo regularidade ao exercício da atividade empresária, enquanto que o artigo 971 do Código Civil ao regular a hipótese do produtor rural que deseja equiparar-se a empresário individual o registro atribui-se apenas dois efeitos: constitutivo da condição de empresário e atribui-lhe regularidade no exercício da atividade empresária, e só, de modo que não se coadura com a constituição de uma EIRELI que como vimos é uma forma apta a constituir uma sociedade.

12 Empresa é atividade econômica organizada dos fatores produtivos com o fim de produzir e circular bens e prestar serviços.

13 O Manual da EIRELI (item 5.2 e 5.2.1) que acompanha a IN DREI n ${ }^{\circ} 81 / 20$, no mesmo sentido.

14 Enunciado 468 CJF: Art. 980-A: A empresa individual de responsabilidade só poderá ser constituída por pessoa natural. (CJF, 2012, p. 76). 
infralegal, do Departamento de Registro Empresarial e Integração (DREI), mais precisamente o Manual de Registro da EIRELI vedava essa possibilidade, contudo em 2018, André Ramos Santa Cruz (RAMOS, 2015, p. 45) que hoje é Diretor do DREI e capitaneou a alteração dos Manual de Constituição da EIRELI ${ }^{15}$ passou a admitir expressamente que ela possa ter sócio pessoa jurídica não havendo mais óbice ao registro.

Após essa modificação regulamentar, que autorizou a constituição de EIRELI integrada por pessoa jurídica, na III Jornada de Direito Comercial do CJF, foi aprovado o seguinte enunciado sobre o tema, que ainda esclarece sobre a limitação de quantas EIRELI a pessoa natural pode constituir: "Enunciado 92 CJF Comercial: A Empresa individual de Responsabilidade Limitada (EIRELI) poderá ser constituída por pessoa natural ou por pessoa jurídica, nacional ou estrangeira, sendo a limitação para figurar em uma única EIRELI apenas para a pessoa natural.” (CJF, 2019, p. 7).

Aproveitando o conteúdo do enunciado acima transcrito, o artigo 980-A $\S 2^{\circ}$ do Código Civil limita, para pessoa natural, a constituição de uma única EIRELI, limitação que não existe, segundo a doutrina: Alves (2014, p. 148), Nunes (2014, p. 89), Travassos (2015, p 194), Tomazette (2017, p. 64), em relação à integrante pessoa jurídica e que o enunciado fez questão de esclarecer. Aliás o Manual de Constituição da EIRELI, do DREI segue nesse mesmo sentido.

A ausência de registro dos atos constitutivos da EIRELI no registro competente, coloca a EIRELI na condição de irregular, conforme estabelece o enunciado 471 da V Jornada de Direito Civil do CJF: "Enunciado 471 CJF: Os atos constitutivos da EIRELI devem ser arquivados no registro competente, para fins de aquisição de personalidade jurídica. A falta de arquivamento ou de registro de alterações dos atos constitutivos configura irregularidade superveniente." (CJF, 2012, p. 76).

Merece consideração, o questionamento suscitado por Travassos $(2015$, p. 182) acerca da EIRELI sem registro ser ou não uma sociedade em comum ${ }^{16}$. Em que pese o teor do enunciado acima, o questionamento é deveras pertinente haja vista que, por definição, a pessoa natural que exerce em nome próprio a atividade empresária é o empresário individual, tenha ele registro ou não, o que definirá como empresário individual regular ou empresário individual irregular. Contudo, se a EIRELI tem apenas um sócio, pessoa natural, fica difícil definir sob qual forma pretendia exercer a atividade econômica e, por conseguinte se ele será empresário individual irregular ou uma EIRELI em comum.

Em sendo a EIRELI uma forma societária apta a formar uma sociedade, em princípio, seria possível que ela fosse constituída de fato e a ela ser aplicada o regime das sociedades em comum, regulada no artigo 986 a 990 do Código Civil. Comungamos com a orientação formulada por Travassos (2015, p. 185) de que o regime das sociedades em comum não poderia lhe ser aplicável porquanto daria margem à interpretação mais favorável ao sócio único de uma EIRELI irregular, do que no exercício como empresário individual regular ou irregular, sobretudo no primeiro caso, como bem observa:

\section{$[\ldots]$}

Admitir-se, pois, a EIRELI sem registro como sociedade em comum e capaz de atrais o regramento dos artigos 986 a 990 do Código Civil representaria incompatível benefício em favor do sócio único da EIRELI que optasse por atuar na irregularidade e sem registro, em detrimento do empresário individual

15 IN DREI $n^{\circ} 38 / 2017$, cujo item 1.1.2, I b) foi alterado pela IN $n^{\circ}$ DREI 69/2018, atualmente nesse mesmo sentido é o item 3 do Manual da EIRELI anexo a IN DREI n 81/20, publicada no DOU de 15/06/2020.

16 Estamos levando em consideração apenas a atividade empresária em relação a pessoa natural, uma vez que quem não exerce a atividade empresária, em sendo pessoa natural, não será empresário individual, nem exigirá registro. No entanto, em se tratando de sócio pessoa jurídica, a pergunta será: a pessoa jurídica estará exercendo em nome próprio ou será uma EIRELI em comum? 
regularmente constituído e sem registro.

[...] (TRAVASSOS, 2015, p. 185).

Não há diferença de interpretação, em se tratando de sócio único pessoa jurídica, como se vê Travassos (2015, p. 188):
$[\ldots]$
Caso admitida pessoa jurídica como sócia instituidora de EIRELI (tema que será tratado no próximo item), também não se estará diante de uma sociedade em comum, mas de atuação direta da sociedade instituidora em nome próprio, a qual responderá integralmente pelas dívidas assumidas na exploração da atividade designada para a EIRELI em formação. [...]

A EIRELI pode nascer orginalmente sob essa forma societária ou pode derivar da transformação própria ou imprópria ${ }^{17}$, tal como faculta o artigo 980-A, $\S 3^{\circ}$ do Código Civil.

É possível que o impedido ao exercício da atividade empresária seja integrante de uma EIRELI, desde que não exerça a administração, já que o artigo 980-A, § $6^{\circ}$ do Código Civil, determina a aplicação subsidiária das regras de sociedades limitadas, a qual permite a nomeação de administrador não sócio - leia-se, não integrante da pessoa jurídica —, conforme preceitua o artigo 1.061 do Código Civil. O administrador da EIRELI não pode ser impedido (artigo 1.011, $\S 1^{\circ}$ do Código Civil), não pode ser pessoa jurídica, nem precisa ser sócio - em sendo sócio pessoa jurídica nem poderia ser por vedação expressa do Manual da EIRELI anexo a Instrução Normativa DREI $n^{\circ} 81 / 20$, publicada no DOU em 15/06/2020, no item 3.2.

Conforme dispõe o artigo 980-A, $\S 1^{\circ}$ do Código Civil, a EIRELI permite a escolha entre firma individual ou denominação, sempre acrescida da sigla EIRELI no final.

O regime de responsabilidade do seu integrante é limitada. Como seu capital social nasce integralizado, não há que se falar em responsabilidade do sócio pelas obrigações sociais, contudo, em razão as inovações trazidas pelo Manual da EIRELI anexo à IN DREI $n^{\circ} 81 / 20$, publicada no DOU em 15/06/2020, agora é permitido que o capital social não seja integralizado simultaneamente a subscrição tanto no que se refere aquilo que exceder o 100 (cem) salários mínimos, quanto com relação a posteriores aumento de capital. Em razão, o capital não integralizado permanece sob a responsabilidade do sócio, tal como ocorre com a sociedade limitada, excluída a solidariedade já que não há outros sócios.

A doutrina, a partir da inovação normativa que altera o conteúdo do artigo 1.052 do Código Civil e permite a sociedade limitada unipessoal, tem se perguntado é se a EIRELI continuará sendo útil.

O artigo 980-A do Código Civil não foi revogado e, portanto, a EIRELI continua sendo uma forma societária unipessoal permanente apta a desenvolver atividades empresárias ou não, daí merece também ter a sua divisão de resultados analisada.

\section{A DIVISÃO DOS RESULTADOS NA SOCIEDADE LIMITADA E NA EIRELI}

Partindo-se da importância contemporânea destes dois tipos societários, que foram analisados em suas características gerais, passemos então a uma análise deste viés pouco explorado pela doutrina que é a distribuição de seus resultados entre os sócios.

Seguindo a teoria geral do direito societário, que se baseia nas regras do regime jurídico próprio das sociedades simples, todo contrato social deve indicar a participação dos sócios nos

17 Borba (2012, p. 498) entende que a mudança da forma empresário individual para qualquer forma societária, constituiria transformação imprópria. 
lucros e nas perdas sociais, tal como enuncia os artigos 997, VII e o artigo 1.008 do Código Civil que eiva a cláusula que exclua qualquer sócio de participação com o vício de nulidade.

Assim, excluir um sócio de participar das perdas ou dos resultados da sociedade que integra viola preceito de ordem pública capaz de viciar o conteúdo do contrato social.

Com relação as perdas sociais a sociedade limitada e a EIRELI dispensam cláusula contratual a respeito.

Cada tipo societário regulará, em seu regime jurídico o grau de responsabilidade de cada sócio, ou categoria de sócios, para com as obrigações sociais. No entanto, na sociedade do tipo simples, na sociedade em nome coletivo e na sociedade em comandita simples, será possível regular no contrato, com efeitos com relação aos sócios e as obrigações sociais com terceiros ou não, o grau de responsabilidade que poderá variar a teor do disposto nos artigos 997, VIII, 1.007, 1.023, 1.039, parágrafo único e 1.046, parágrafo único todos do Código Civil.

A sociedade limitada e a EIRELI não têm regra semelhante, já que sua participação nas perdas é determinada pelo seu próprio regime jurídico de responsabilidade dos sócios a teor do disposto no artigo 1.052, caput e 980-A todos do Código Civil.

A responsabilidade dos sócios pelas obrigações da sociedade com terceiros se dá até o limite do capital social.

No caso da EIRELI, com a recém alteração da regulação infralegal operada pelo DREI na IN DREI $n^{\circ} 81 / 20$, publicada no DOU 15/06/2020, em relação a parcela do capital cuja integralização imediata não é mais obrigatória - a teor do que se disse acima, cuja leitura remetemos o leitor —, sua responsabilidade perdurará até a sua integralização e, no caso da sociedade limitada, a responsabilidade, que será solidária entre os sócios enquanto o capital social não for integralizado.

Em ambos os tipos societários, a reponsabilidade se extingue assim que a integralização se completa. Isso ocorre também na hipótese de aumento de capital.

Não é por acaso que a EIRELI e a sociedade limitada são os tipos societários mais escolhidos dentre os disponíveis no ordenamento jurídico brasileiro. Basicamente o seu risco de perda é o risco do investimento feito pelo sócio ou pelos sócios, sendo que na sociedade limitada haverá solidariedade pelo capital não integralizado. Essa limitação da responsabilidade, é, segundo Easterbrook e Fischel (1991, p. 41) o arranjo pelo qual as perdas são protegidas, controladas, e cada investidor tem um limite para a perda que suportará, exatamente ao contrário do que ocorre em um regime de responsabilidade ilimitada no qual os sócios suportarão, em tese, todo o custo da perda em caso de insucesso.

A análise da divisão do resultado pretendida nesse trabalho deve iniciar-se pelo artigo 1.007 do Código Civil, que assim dispõe: “Art. 1.007. Salvo estipulação em contrário, o sócio participa dos lucros e das perdas, na proporção das respectivas quotas, mas aquele, cuja contribuição consiste em serviços, somente participa dos lucros na proporção da média do valor das quotas." (BRASIL, 2002, grifo nosso).

Antes de prosseguir-se na análise duas premissas precisam ser estabelecidas, a primeira diz respeito a aplicabilidade desse dispositivo às sociedades limitadas e a EIRELI.

Os capítulos normativos que regulam estes dois tipos societários não regulam expressamente o tema, - divisão de resultado entre os sócios - contudo, o artigo 1.054 do Código Civil ${ }^{18}$ impõe à sociedade limitada a observância das cláusulas do contrato social seguindo, no que couber, o disposto no artigo 997 do mesmo diploma, que entre outras cláusulas, deve estabelecer “a participação de cada sócio nos lucros e nas perdas". O mesmo vale para a EIRELI por força do artigo 980-A, $\S 6^{\circ}$ do Código Civil, que determina que a ela é aplicável as regras de sociedade limitada, no que couber, e como a sociedade limitada prevê, em seu regime o artigo 1.054 do

18 Não é o caso de se analisar a aplicação do artigo 1.053, caput e parágrafo único do Código Civil, haja vista que o artigo 1.054 do Código Civil, é regra de observância obrigatória no tipo societário limitada, ainda que obedeça a hermenêutica da compatibilidade da cláusula ao regime da sociedade limitada. 
Código Civil, tal regra deve ser estendida também a EIRELI.

De igual modo, não há no regime jurídico da sociedade limitada e da EIRELI regra que regule essa partilha do resultado, razão pela qual por força do artigo 1.053 do Código Civil, aplicase o disposto no artigo 1.007 do mesmo diploma legal.

Essa conclusão é simples, quando a sociedade não utiliza a prerrogativa contida no parágrafo único do art. 1.053 do Código Civil, mas se a sociedade limitada tiver optado pelo regime supletivo das normas de sociedade anônima, a resposta é a mesma, contudo o fundamento legal mudará, já que nas sociedades por anônimas as cláusulas estatutárias submetem-se a teoria geral do direito societário por força do artigo 83 da Lei no 6.404/76, mas a distribuição de dividendos obedecerá ao disposto nos artigos 201 a 205 da mesma lei ${ }^{19}$.

E a segunda premissa, diz respeito ao alcance do artigo 1.007 do Código Civil.

A segunda parte do dispositivo que trata da contribuição com serviços não é aplicável às sociedades limitadas ou a $\operatorname{EIRELI}^{20}$, por força do disposto no artigo 1.055, $\S 2^{\circ}$ do Código Civil que veda expressamente essa possibilidade.

Estabelecidas essas premissas, vê-se que a divisão de resultado, leia-se, lucro, é cláusula obrigatória no contrato social.

Acostumamo-nos a ver, na grande maioria dos contratos sociais registrados—, que seguem modelos disponíveis na internet - apenas a divisão do capital social em quotas e sua distribuição entre os sócios, mas não cláusulas que estabelecem de forma clara, explícita ou mesmo arrojada, a distribuição do resultado.

Em decorrência disso, igualmente nos acostumamos a repetir como um mantra que a participação nos lucros é proporcional a participação no capital social (NEGRÃO, 2015, p. 356). E isso é verdade? É, mas pode não ser.

A resposta acima pode parecer contraditória ou paradoxal, mas não poderia ser diferente. Isso porque o simples fato de a divisão do resultado ser desse modo, na ampla maioria dos casos, já que as sociedades limitadas e EIRELI constituídas, usam modelos contratuais prontos que sequer são elaborados por advogado habilitado, e que são silentes em relação a partilha do resultado, aplicando-se, nesse caso, a "regra geral da proporção das respectivas quotas", prevista no próprio texto legal do artigo 1.007 do Código Civil.

Por outro lado, por uma análise literal do disposto no citado artigo é possível afirmar, sem pestanejar, que pode não ser proporcional, já que a expressão "salvo disposição em contrário" denota a plasticidade da cláusula de divisão de resultado (CAMPINHO, 2016, p. 104; GONÇALVES NETO, 2016, p. 234; RAMOS, 2015, p. 280).

Essa plasticidade permite, sem grandes questionamentos, arranjos como a criação de reservas de capital, o que não se contesta, haja vista que criar reservas implica em planejar o futuro e o crescimento da sociedade.

Igualmente permite, a distribuição preferencial de lucro a determinado sócio ou sócios, bastando para tanto a criação de quotas preferenciais, que não tem previsão legal expressa no regime jurídico da sociedade limitada, mas que já é admitida na prática desde a alteração do Manual de Registro das Sociedade Limitadas, pela Manual das Sociedade Limitadas anexo a IN DREI $^{\circ}$ 38/2017, que regulou o tema no item 1.4, e agora ainda mais bem detalhada pelo Manual da Sociedade Limitada anexo a IN DREI no $81 / 20$, publicada no DOU 15/06/2020, no item 5.3.1. ${ }^{21}$

19 Em razão dos estreitos limites deste trabalho não será feita análise da distribuição dos resultados para as sociedades limitadas cujo contrato social tenha optado pela aplicação supletiva das normas de sociedades anônimas, o que se pretende fazer em outra oportunidade.

20 A bem da verdade na EIRELI, que é essencialmente uma sociedade unipessoal, essa disposição seria dispensada por sua total incompatibilidade com essa característica.

21 Não nos aprofundaremos nessa hipótese porquanto as quotas preferenciais, segundo a referida instrução normativa, exigem como pressuposto a opção pela regência supletiva da Lei $\mathrm{n}^{\circ} 6.404 / 76 \mathrm{e}$, agora podem, inclusive, ser emitidas sem direito a voto. 
Em que pese o posicionamento do Departamento de Registro Empresarial e Integração (DREI) contido no item 5.3.1. da referida norma infralegal, com ela não concordamos, em dois pontos, o primeiro diz respeito ao transbordamento do poder regulamentar do referido órgão que pressupõe regência supletiva pelas normas de sociedade anônima para o contrato que cria quotas preferenciais, ainda que não o tenha feito de modo expresso, em colidência direta ao disposto no parágrafo único do artigo 1.053 do Código Civil, que assim o exige. E, em segundo lugar, que o mesmo esforço hermenêutico que a doutrina sempre fez para admitir a quota preferencial não é incompatível com sociedades limitadas sem opção pela regência supletiva das normas de sociedade anônima, já que a teoria geral dos contratos e a teoria geral do direito societário, valendo-se do conteúdo do artigo 1.007 do Código Civil são perfeitamente capazes de preencher as lacunas do regime jurídico da sociedade limitada.

De igual modo, essa maleabilidade facultada pelo disposto no artigo 1.007 do Código Civil também seria uma porta aberta para criação de cláusula que determine uma destinação certa e específica de parte dos resultados societários, que não a distribuição entre os seus sócios, como uma finalidade institucional.

Isso permitiria criar sociedades limitadas e EIRELI que tenham dentro do seu fim lucrativo um fim adjacente que imponha a sociedade o dever contratual de fazer algo com parte desse lucro, que, por óbvio, não é destiná-lo a seus sócios, estabelecer preferência ou criar reservas de contingência, a espelho do que já se vê com relação as benefit companies ${ }^{22}$.

A ideia seria entregar parte dos resultados como contrapartida a sociedade, a comunidade, aos empregados, ou para conter, minimizar ou neutralizar as externalidades decorrentes da atividade econômica exercida, ou outro fim, do qual a sociedade tivesse interesse em abraçar como "causa".

Existe uma assimetria estrutural entre o Estado, os grupos do capital e do trabalho, em certa medida, decorrente da relação assimétrica de dependência entre os detentores dos meios de produção e os detentores da força de trabalho (CORREA; CLARK; RICEPUTI, 2017, p.7172), cujas engrenagens naturais não têm sido capazes de equilibrar, e as ideias acima sugerem possibilidades que permitem soluções endógenas, à margem, mas não desconforme, com o livre mercado estabelecido pela nossa constituição econômica.

Em alguns casos, cláusulas dessa natureza, poderiam ser usadas para neutralizar total ou parcialmente o custo do capital, decorrente da irresponsabilidade dos sócios em modelos societários que a limitam.

Em uma análise muito interessante sobre o tema, Easterbrook e Fischel (1991, p. 44), observam, sob a perspectiva dos regimes societários de responsabilidade limitada, como isso implica numa ação mais arrojada e irresponsável da sociedade, promovida pelos seus administradores, já que seus sócios tornar-se-iam irresponsáveis a partir da integralização do capital social. A partir daí esses autores analisam algumas soluções para equilibrar distorções sistêmicas e também para conter esse contrassenso como a aplicação da teoria da desconsideração da personalidade jurídica, celebração de contrato de seguro e ainda um conjunto de métodos alternativos com o objetivo de conter esse "perigo moral" como um capital social mínimo exigido, um seguro obrigatório/ compulsório, um regime de responsabilidade dos administradores mais severo e uma regulação específica sobre o tema.

Sem contrariar a ideias trazidas por esses autores, um dos vieses possíveis da plasticidade da cláusula de distribuição de resultado seria a criação institucionalizada de uma reserva de capital destinada a assegurar o risco da atuação dos administradores da sociedade, permitindo uma administração mais arriscada, sem se descurar a proteção de terceiros.

22 Em linhas bem gerais, benefit company é um tipo de sociedade com fins lucrativos, já admitida no direito comparado, que inclui como um de seus objetivos institucionais o impacto positivo na sociedade, trabalhadores, comunidade e meio ambiente, além do lucro. Esse objetivo é legal e não contratual ou estatutariamente definido, o que difere da proposição ora apresentada. Não há nada semelhante hoje no ordemanto jurídico brasileiro. 
Essas medidas sugeridas permitem em maior ou menor proporção equacionar externalidades dentro desses dois modelos societários, seja do ponto de vista endógeno, seja do ponto de vista exógeno, de modo a equilibrá-las.

O questionamento da alternativa acima proposta como incremento do custo do capital é óbvio e natural, partindo de um raciocínio dialógico, mas essa alternativa se mostra compatível para quem está disposto a tornar-se sócio de uma instituição que exerce a atividade econômica com uma dose a mais de responsabilidade social.

É o que Rossignoli e Almeida (2018, p. 231) citam como capitalismo inclusivo, onde o Estado busca instigar o crescimento inclusivo social, focada no indivíduo e suas capacidades e gere um retorno positivo. E não é só, essa perspectiva inclui uma sustentabilidade centrada na solidariedade e na ética (ROSSIGNOLI; ALMEIDA, 2018, p. 238), como se vê em sua conclusão:

\begin{abstract}
$[\ldots]$
Destaca-seaqui,opapeldo 'homoempreendedor'atuantenessemodernocapitalismo inclusivo, planeja-se não apenas prevendo os riscos de seu empreendimento; prevê a inserção do crescimento inclusivo como algo tão importante quando o seu crescimento econômicos, visando, combater, efetivamente, os níveis de desigualdade sociais, através de práticas que possibilitem ampliação de uma cultura empresarial responsável, produtora de responsabilidade e solidariedade social (ROSSIGNOLI; ALMEIDA, 2018, p. 238).
\end{abstract}

Essas ideias pressupõem uma mudança na mentalidade do investidor, contudo, os operadores do direito precisam estar conscientes das possibilidades que nosso sistema jurídico é capaz de proporcionar.

Imagina-se que o leitor deve ter se questionado durante a leitura deste breve ensaio a utilidade desse tema, com relação a EIRELI e a sociedade limitada unipessoal, mas diante dos argumentos acima dispendidos buscou-se demonstrar que essa "inutilidade" não é tão meridiana quanto parece, já que essa plasticidade acerca da partilha dos resultados é plenamente possível nesses casos, basta que o sócio queira e escolha.

\title{
CONCLUSÃO
}

Como dito diversas vezes ao longo deste trabalho, a distribuição dos resultados entre os sócios, nas sociedades limitadas e na EIRELI é assunto pouco explorado pela doutrina, não obstante, como vimos, exista margem e plasticidade para isso.

O que se buscou neste breve estudo, foi demonstrar a partir da análise da divisão de resultados entre os sócios a maleabilidade desse tipos societários, como podem apresentar múltiplas possibilidades que, por sua vez, podem implicar em inovações institucionais significativas e como isso mudar o sentido do que é objetivo social, já que no sistema capitalista de apropriação privada o lucro exclusivo dos investidores e sua divisão entre eles não precisa ser, e num mundo moderno e globalizado, não deve ser, o único objetivo almejado. Isso tem a ver, com a denominada nova empresarialidade ${ }^{23}$, que rompe o paradigma de que na exploração da atividade econômica empresária a busca do lucro é um fim em si mesmo.

Em que pese o Brasil, indubitavelmente, constituir-se em um Estado capitalista, como se vê da ordem constitucional econômica regulada a partir do artigo 170 da Constituição Federal,

23 A ideia de nova empresarialidade gira em torno do exercício da atividade empresária seguindo padrões éticos e de valores éticos, que culminam por tornar a empresa, em seu sentido técnico-jurídico, geradora de externalidades positivas no que tange as partes relacionadas sejam elas outros empresários, empregados, colaboradores, consumidores, fornecedores e também, o poder público e com isso agregando valor. 
este se subsume a princípios notadamente sociais, impondo a todos que operam neste ambiente livre que tenham como preocupação princípios como a valorização do trabalho humano, a justiça social, a função social da propriedade, a defesa do meio ambiente, a defesa do consumidor, a redução de desigualdades regionais, a busca do pleno emprego e, também, o tratamento favorecido ao pequeno empresário.

Nitidamente, existem objetivos macroeconômicos que precisam ser a espinha dorsal da política do Estado brasileiro, contudo, tais princípios não são incompatíveis com o exercício livre da atividade econômica e a empresa, em seu sentido técnico-jurídico, e, particularmente, as sociedades ora estudadas, podem representar um avanço significativo em direção a um mundo globalizado e melhor para o ser humano, já que a Dignidade da Pessoa Humana corresponde fundamento da nossa República e de todo Estado Democrático de Direito que se prese.

Como bem observa, Grau (2010, p. 192), citando José Afonso da Silva (2009), a Constituição brasileira é capitalista, mas a liberdade apenas é admitida enquanto exercida no interesse da justiça social e confere prioridade aos valores do trabalho humano sobre todos os demais valores da economia do mercado. Essa observação dialoga perfeitamente com a abordagem acima enunciada e não precisa ser, de modo algum, dissociada da ideia do objetivo lucrativo e foi isso que se buscou demonstrar.

A ideia de mercado, de ordem jurídica de mercado, estudada por Forgioni (2012, p. 166), considera em sua análise a multiplicidade de dimensões as quais está atrelado, quais sejam: a dimensão econômica, política, social e jurídica, isso porque não é uma ordem espontânea e os resultados por ele produzidos derivam de decisões, sobretudo, políticas, tomadas pelos vários atores deste ambiente e os princípios constitucionais acima mencionados são a fôrma que primeiramente lhes moldará. O mercado não existe sem direito, mas seu desenvolvimento darse-á nos espaços deixados pela regra jurídica e é aí que entra a importância da plasticidade e maleabilidade da cláusula de distribuição de resultado objeto deste breve estudo aliada a atuação criativa do advogado ${ }^{24}$.

Assim, observando, autorregulando e moldando os atores microeconômicos deste mercado é possível dar aplicabilidade aos princípios constitucionais, em sua dimensão social, já que o Estado brasileiro, que tem o papel de fomentar a atividade econômica, há muito tempo tem tratado o tema política econômica de forma significativamente dissociada destes valores principiológicos. $\mathrm{O}$ exercício da atividade econômica livre não precisa ser exercido à margem de princípios que a República Federativa do Brasil escolheu acolher.

Buscamos mostrar que os tipos societários que analisamos, dispõem de ferramentas aptas e disponíveis, cabendo aos atores dessa ordem econômica fazer bom uso deles.

\section{REFERÊNCIAS}

ALVES, Alexandre Ferreira de Assumpção. Empresa familiar: estudos jurídicos. São Paulo: Saraiva, 2014.

BORBA, José Edwaldo Tavares. Direito societário. 13. ed. Rio de Janeiro: Renovar, 2012.

BRASIL. Instrução Normativa n. 81, de 10 de Junho de 2020: Dispõe sobre as normas e diretrizes gerais do Registro Público de Empresas, bem como regulamenta as disposições do Decreto $n^{\circ} 1.800$, de 30 de janeiro de 1996. Diário Oficial da União: Seção: 1, Brasília, DF, ano 112, p. 3115 jun. 2020. Disponível em: https://www.in.gov.br/en/web/dou/-/instrucao-

24 Os autores deste artigo defendem aquilo que denominam "advocacia criativa", consistente na atuação do advogado consultor, no limite da lei e na liberdade por ela concedida, em encontrar soluções, construir novos caminhos e prevenir resultados indesejados e produzir resultados desejados. 
normativa-n-81-de-10-de-junho-de-2020-261499054. Acesso em: 27 abr. 2020.

BRASIL. Lei n. 10.406, de 10 de janeiro de 2002. Institui o Código Civil. Brasília, DF: Presidência da República, 2002. Disponível em: http://www.planalto.gov.br/ccivil_03/leis/2002/ L10406compilada.htm. Acesso em: 12 abr. 2020.

BRASIL. Lei $\mathbf{n}^{\mathbf{0}}$ 13.247, de 12 de janeiro de 2016. Altera a Lei ${ }^{\circ}$ 8.906, de 4 de julho de 1994 - Estatuto da Advocacia. Brasília, DF: Presidência da República, 2016. Disponível em: http:// www.planalto.gov.br/CCIVIL_03/_Ato2015-2018/2016/Lei/L13247.htm. Acesso em: 12 abr. 2020 .

BRASIL. Lei no 13.874, de 20 de setembro de 2019. Institui a Declaração de Direitos de Liberdade Econômica; estabelece garantias de livre mercado; [...]. Brasília, DF: Presidência da República, 2019. Disponível em: http://www.planalto.gov.br/ccivil_03/_ato2019-2022/2019/lei/ L13874.htm. Acesso em: 27 abr. 2020.

BRASIL. Ministério da Fazenda. Exposição de motivos 196, de 24/06/1976. Brasília, DF: Ministério da Fazenda, 1976. Disponível em: http://www.cvm.gov.br/export/sites/cvm/legislacao/ leis-decretos/anexos/EM196-Lei6404.pdf. Acesso em: 27 abr. 2020.

CAMPINHO, Sergio. Curso de direito comercial: direito de empresa. 14. ed. São Paulo: Saraiva, 2016.

CJF - CONSELHO DA JUSTIÇA FEDERAL. JORNADA DE DIREITO CIVIL, 5., 2012, Brasília. Enunciados [...]. Brasília: Conselho da Justiça Federal, 2012. Disponível em: https:// www.cjf.jus.br/cjf/corregedoria-da-justica-federal/centro-de-estudos-judiciarios-1/publicacoes-1/ jornadas-cej/vjornadadireitocivil2012.pdf. Acesso: 9 mar. 2021

CJF - CONSELHO DA JUSTIÇA FEDERAL. JORNADA DE DIREITO COMERCIAL, 1. 2013, Brasília. Enunciados [...]. Brasília: Centro de Estudos Judiciários, 2013. Disponível em: https://www.cjf.jus.br/cjf/corregedoria-da-justica-federal/centro-de-estudos-judiciarios-1/ publicacoes-1/jornadas-de-direito-comercial/livreto-i-jornada-de-direito-comercial.pdf. Acesso: 9 mar. 2021

CJF - CONSELHO DA JUSTIÇA FEDERAL. JORNADA DE DIREITO COMERCIAL, 2 ., 2015, Brasília. Enunciados [...]. Brasília: Centro de Estudos Judiciários, 2015. Disponível em: https://www.cjf.jus.br/cjf/corregedoria-da-justica-federal/centro-de-estudos-judiciarios-1/ publicacoes-1/jornadas-de-direito-comercial/enunciados_aprovados-referencia_legislativajustificativa_ii_jornada.pdf. Acesso: 9 mar. 2021

CJF - CONSELHO DA JUSTIÇA FEDERAL. JORNADA DE DIREITO COMERCIAL, 3. 2019, Brasília. Enunciados [...]. Brasília: Centro de Estudos Judiciários, 2019. Disponível em: https://www.cjf.jus.br/cjf/corregedoria-da-justica-federal/centro-de-estudos-judiciarios-1/ publicacoes-1/jornadas-de-direito-comercial/enunciados-aprovados-iii-jdc-revisados-2.pdf. Acesso: 9 mar. 2021

CORREA, Leonardo Alves; CLARK, Giovani; RICEPUTI, Marcelo. Constituição econômica, desenvolvimento e a institucionalização do princípio do pleno emprego: uma abordagem à luz da teoria da eletividade de Claus Offe. Revista de Direito Econômico e Socioambiental, Curitiba, v. 8 , n. 3, p. 67-92, set./dez. 2017. doi:10.7213/rev.dir.econ.soc.v8i3.18426. 
EASTERBROOK, Frank H.; FISCHEL, Daniel R. The economic structure of corporate law. Cambridge: Harvard Univesty Press, 1991.

FORGIONI, Paula A. A evolução do direito comercial brasileiro: da mercancia ao mercado. 2. ed. São Paulo: Editora Revista dos Tribunais, 2012.

FRIEDMAN, Milton. Livre para escolher. Tradução de Lígia Filgueiras. Rio de Janeiro: Record, 2015.

GONÇALVES NETO, Alfredo de Assis; Direito da empresa: comentários aos artigos 966 a 1.195 do Código Civil. 6. ed. São Paulo: Editora Revista dos Tribunais, 2016.

GRAU, Eros Roberto; A ordem econômica na constituição de 1988. 14. ed. São Paulo: Editora Malheiros, 2010.

JUCERJA - JUNTA COMERCIAL DO ESTADO DO RIO DE JANEIRO.

Constituição de Empresas no ano de 2020 e 2019. Rio de Janeiro:

JUCERJA, 2020. Disponível em: https://www.jucerja.rj.gov.br/Informacoes/

caComparativa?AnoBaseConsulta=2020\&AnoConsultaComparativo=2019\&TipoDeConsulta=1. Acesso em: 27 abr. 2020.

NEGRÃO, Ricardo. Manual de direito comercial \& de empresa: teoria geral da empresa e direito societário. 12. ed. São Paulo: Saraiva, 2015.

NUNES, Márcio Tadeu Guimarães. EIRELI: A Tutela do Patrimônio de Afetação: o reforço à proteção do patrimônio pessoal do empreendedor à luz da Lei no ${ }^{\circ}$ 12.441/2011, São Paulo: Quartier Latin, 2014.

RAMOS, André Luiz Santa Cruz. Direito empresarial esquematizado. 5. ed. Rio de Janeiro: Forense; São Paulo: Método, 2015.

ROSSIGNOLI, Marisa; ALMEIDA, Patrícia Silva de. Governamentalidade neoliberal: reflexões sobre o crescimento econômico e o crescimento inclusivo. Revista de Direito Econômico e Socioambiental, Curitiba, v. 9, n. 3, p. 219-242, set./dez. 2018. DOI: 10.7213/rev.dir.econ.soc. v9i3.23440.

TOMAZETTE, Marlon. Curso de direito empresarial: teoria geral e direito societário. 8. ed. São Paulo: Atlas, 2017. v. 1.

TRAVASSOS, Marcela Maffei Quadra. Empresa Individual de Responsabilidade Limitada (EIRELI): Análise constitucional do instituto, unipessoalidade e mecanismos de controle de abusos e fraudes. Rio de Janeiro: Renovar, 2015.

Como citar: GANTOIS, Simone Menezes; SANT'ANNA, Leonardo. Sociedade limitada e EIRELI: uma análise sobre a divisão dos resultados. Scientia Iuris, Londrina, v. 25, n. 1, p. 68-86, mar. 2021. DOI: 10.5433/2178-8189.2018v25n1p68. ISSN: 2178-8189. 
Recebido em 11/08/2020

Aprovado em 09/03/2021 